\title{
TRATAMIENTOS DEL TEMA SÁFICO EN ALGUNAS PIEZAS DE TEATRO MEXICANO
}

\author{
Hugo Salcedo Larios \\ Universidad Iberoamericana Ciudad de México
}

\section{RESUMEN}

En México son menos conocidos los materiales dramáticos que se refieren al asunto lésbico, sean o no escritos por mujeres. Si bien la comunidad diversa ha ido logrando espacios de manifestación cultural y de visibilidad, en el teatro todavía prevalece una baja cuota de exposiciones cuyo asunto privilegie las presencias sáficas. Existe en este sentido un continuum lesbiano desconocido, oculto o intencionalmente desplazado como consecuencia también de una marginación social y política pero también cultural. En este artículo se revisan algunos textos teatrales en donde la personaje sáfica privilegia su presencia encarando prioritariamente los roles protagónicos, con el fin de explicitar los tratamientos, las técnicas y estrategias de exposición utilizadas por sus autores.

Palabras Clave: análisis de textos, teatro mexicano, diversidad sexual, dramaturgia lésbica.

\section{THE SAPPHIC ISSUE IN SOME THEATRICAL PIECES OF MEXICAN DRAMA}

\section{Abstract}

In Mexico the dramatic materials dealing with the issue of lesbianism, whether or not written by women, are not well known. While the diverse community has achieved spaces of cultural manifestation and visibility, in the theatre a low share of exhibitions emphasizing "Sapphic presences» still prevails. There is in this sense a lesbian continuum unknown, hidden or intentionally displaced as a consequence of a social, political as well as cultural marginalization. This article reviews some theatrical texts where the Sapphic character favors her presence dealing primarily with the starring roles, in order to explain treatments, techniques and exhibition strategies used by their authors.

Keywords: text analysis, Mexican Theatre, sexual diversity, lesbian drama. 


\section{INTRODUCCIÓN}

En contrapartida a las numerosas piezas dramáticas de corte homoerótico donde se privilegian las variantes de relaciones afectivas y sexuales entre varones, se conoce mucho menos material dramatúrgico que se refiera -o tan solo infiera- el asunto lésbico, razón por la cual llevar a cabo un estudio de esta naturaleza encuentra su sentido, a la vez que permite refrendar la postura imperante de su desplazamiento, colocando a esta producción literaria en un lugar -permítase la expresióna las orillas de la marginalidad.

La pretensión de este artículo no es de reivindicación ni militancia porque el hecho literario o estético no requiere de factura de aprobación. Se intenta por tanto -y solamente- proponer un esquema de aproximación que considere algunas visibilidades del asunto sáfico aparecido en un corpus de textos del teatro de México, sabedor de que toda anotación habrá de resultar incompleta. Esta cualidad ha de comprometer, en un tiempo cercano, la realización de una pesquisa más amplia e insistente.

Para elaborar el estudio se consideraron los textos publicados y en algunos casos también algunas peculiaridades de sus puestas en escena. Las piezas para teatro se leen intentando hacer un recorrido cronológico pero, ante todo, con la intención de proponer un diálogo entre sus argumentos y estrategias, a fin de considerar un esquema más de semejanzas que de drásticas oposiciones en sus tratamientos.

El tema sáfico en el teatro, como puede desprenderse de lo anterior, es una manifestación muy atractiva para la inmersión y su descubrimiento. En las aproximaciones se utilizan algunas ideas hermenéuticas para la interpretación de los textos, considerando a su vez claves de Anne Ubersfeld y José-Luis García Barrientos para el comentario de los dramas. También se toman en cuenta ciertos conceptos de autores como Foucault y Leticia Sabsay, que aportan nociones de la vigilancia y el castigo, la performatividad de los géneros y la presencia de las diversidades sexuales.

\section{LOS AÑOS CINCUENTA: REVUELTAS Y CASTELLANOS}

Cuando comienza la década de los años cincuenta, se asomaba tímidamente en el escenario de la ciudad de México un joven personaje homosexual dentro de la obra Los signos del Zodiaco de Sergio Magaña (1924-1990), pieza que fuera estrenada en el Palacio de Bellas Artes en 1951. Sin embargo, justo un año antes, en 1950, se habría adelantado José Revueltas (1914-1976) con su texto dramático El cuadrante de la soledad, estrenado en el Teatro Arbeu (ubicado en la actual sede de la Asamblea Legislativa del gobierno de la capital del país) con diseños escenográficos del afamado Diego Rivera, en donde tiene lugar una revelación de índole lésbica. En esta pieza, la joven Piedad relata a "el Parches», su padrino ciego, un suceso del que se percató durante su pasada estancia en la Correccional para mujeres: «Una noche descubrí a dos muchachas, en el salón de inodoros, cuando ya todo mundo dormía... Allá, esa clase de relaciones se castiga sin mise- 
ricordia... Al verse descubiertas, me suplicaron de rodillas, con lágrimas en los ojos, que no las denunciara [...]»1.

Puede observarse en este pasaje la poquedad de la expresión de Piedad, donde los silencios marcados por los puntos suspensivos dejan incompleta su descripción, esbozando a su vez un acto inconcluso que incentiva la imaginación de su padrino y la construcción del dibujo lésbico que de forma tan concreta da cuenta del espacio, lugar y tiempo de esa realización vedada. Lugar: área de los retretes; tiempo: por la noche; circunstancia: cuando todo el mundo duerme.

La naturaleza del drama, explica José-Luis García Barrientos, «implica la orientación oral del diálogo dramático, cuya condición mínima será que, aunque haya sido escrito previamente, pueda ser dicho» ${ }^{2}$, es decir, pronunciado. Sin embargo, en el fragmento arriba anotado, los puntos suspensivos son indicios del acto reprobable que Piedad observó en la cárcel. Esta modalidad detona en la apreciación del lector/espectador y permite la construcción de la expectativa que provoca el interés por el discurso. En otras palabras, lo no dicho y solo sugerido resulta todavía más revelador.

Por su parte, vale mencionar que el panóptico foucaultiano procede a marcar la imposición de la disciplina. La Correccional es el inmejorable espacio de la anatomía política confiada a la reclusión como un castigo para las transgresoras. Sin embargo, como en la película silente de Jean Genet Un chant d'amor (Una canción de amor), filmada también en el año de 1950, donde los presos se erotizan hasta con el humo del cigarro que va de una a otra de las celdas a través del muro, el reclusorio no podrá detener la función erótica de las presidiarias: una y la otra buscan lugar, tiempo y modo para relacionarse sexualmente; la torre central de control se derrumba y no puede percatarse de lo visible, la vigilancia se fractura mediante el ingenio y la necesidad. El procedimiento disciplinario se rompe.

Foucault describe la prisión como el «espacio cerrado, recortado, vigilado en todos sus puntos [...] en el que los menores movimientos se hallan controlados $\aleph^{3}$; sin embargo, frente a la máquina que aparentemente todo lo registra, la exigencia corporal y la agudeza de estas dos mujeres celadas se suman para buscarse un espacio -aunque fugaz- para llevar a cabo el trance amatorio.

En razón del tono directo del lenguaje en El cuadrante de la soledad, la fuerza de las acciones y la resolución dialógica, la experiencia de su montaje escénico, señala Alessandro Rocco, «alcanzó un éxito de público extraordinario y provocó varias polémicas en la prensa de la época» ${ }^{4}$.

${ }^{1}$ J. Revueltas. El cuadrante de la soledad, en Obra reunida IV. El cuadrante de la soledad $y$ dos obras de teatro, México: Era/Centro Nacional de las Artes/Gobierno del Estado de Durango, 2014, pp. 393-452.

2 J.L. García Barrientos. Cómo se comenta una obra de teatro. México: Secretaría de Cultura DF/Paso de gato, 2012.

${ }^{3}$ M. Foucault. Vigilar y castigar. Nacimiento de la prisión, México. Siglo XXI, 2003.

${ }^{4}$ A. Rocco. "José Revueltas dramaturgo y guionista: la obra teatral El cuadrante de la sole$d a d$, características cinematográficas y relaciones intertextuales con algunos guiones cinematográ- 
Dicho lo anterior, se pretende enseguida solo un brevísimo cotejo entre estas dos obras dramáticas mexicanas, tanto por la cercanía temporal entre sus respectivos estrenos como por la coincidencia en el aspecto de la diversidad sexual que -aunque de soslayo- se anuncia. Las piezas, además, circunscriben la peculiaridad de que ambas se desarrollan con la participación de un abundante número de personajes que evolucionan en un ambiente urbano de la pujante ciudad de México en la mitad del siglo pasado.

Tanto en Los signos del Zodiaco como en El cuadrante de la soledad intervienen más de una docena de interlocutores que llevan roles, si bien no protagónicos en sentido estricto, sí necesarios para la comprensión de las tramas, a los que además se suman numerosos caracteres de orquestación: paseantes, miembros de la policía, músicos, clientes, etcétera; la amalgama que se construye a partir de la participación de esta cantidad de personajes produce que sus historias funcionen «como fragmentos de una trama general que incluye a todos. Luego la manera de entrelazarse entre sí de estas pequeñas tramas justifica el recurso [en ambos casos] del escenario múltiple, que funciona como mecanismo técnico para articular el montaje narrativo de la obra ${ }^{5}$. Ambas piezas realizan la descripción de un ambiente decadentista y sórdido de aislamiento, y con capacidades muy limitadas de supervivencia donde la sexualidad descentrada de la heteronormatividad resulta punitiva.

El ritmo de las obras está marcado por la sucesión encadenada de escenas de inflexión melodramática que instalan en perspectiva las historias entrelazadas para el eficaz desarrollo de las acciones múltiples. El tono del melodrama se alcanza mediante el desarrollo del suspenso y la exaltación del sentimiento que descansa en la exploración del carácter en una contraposición constante entre los personajes.

Es también relevante el recurso de la iluminación, cuya focalización se dirige hacia los distintos espacios físicos que a manera de caleidoscopio van mostrando los rasgos de pauperización y miseria espiritual que asfixian las aspiraciones de sus personajes.

En ese ámbito, Piedad, haciendo alusión a su nombre, se compadece de sus compañeras carcelarias prometiendo guardarles el secreto de su intimidad descubierta; sin embargo, una de ellas, incrédula ante el silencio prometido y agobiada por el castigo físico como consecuencia de la probable revelación a las autoridades, intenta suicidarse cortándose las venas, ya que la muchacha, azotada por los golpes en su vida, no alcanza a creer en la bondad de nadie. Esta acción límite de autoinmolación conmueve hondamente a Piedad; luego entonces ella misma se enrola sexualmente activa con la pareja para asegurarles la discreción y secrecía: «Entonces yo tomé el único camino que me quedaba... [...] Les... les demostré... ¿comprendes?

ficos». Graffylia, 13 de mayo de 2014, recuperado de http://cmas.siu.buap.mx/portal_pprd/work/ sites/filosofia/resources/PDFContent/1159/02.pdf. Consultado el 27/06/2017.

5 Ibidem. 
Les demostré sin que les cupiera duda, que yo también podía practicar eso... que yo también era una de sus iguales.... ${ }^{6}$.

A pesar de los lazos de complicidad establecidos mediante la práctica de Piedad con las reclusas, es imposible que ella pueda dar nombre a su acción; el «pecado nefando» al que se refieren las crónicas de los conquistadores se presenta encarnizado contra la figura femenina. En El cuadrante de la soledad esta secuencia confesional de Piedad con su padrino «no presenta ulteriores desarrollos, ya que los dos personajes [el Parches y su ahijada] no vuelven a aparecer en escena, su inserción [entonces] responde [no a una intencionalidad de género u exposición de selección sexual, sino al mero] objetivo estructural de la pieza de alternar situaciones autónomas, pero interconectadas entre sí»?.

Por su parte, Rosario Castellanos (1925-1974) publicó en 1952 Tablero de damas. Esta obra coloca la cuestión lésbica mediante una estrategia diseminada, también muy discreta, aunque en este caso diríase hasta elegante. No se trata del asunto principal de la pieza sino como una línea que conecta la relación afectiva y personal entre Victoria Benavides, secretaria, y Matilde Casanova, su jefa, la protagonista. Ambas son señoras solteronas. La primera se empeña fervorosamente por cumplir con sus tareas como eficiente empleada de la poetisa Matilde, premio Nobel de Literatura que ahora se encuentra de visita en Acapulco. En la obra se reúne a un muy selecto grupo de mujeres escritoras de diversas edades y estados civiles que harán notar, como menciona Laura Guerrero: «La ironía, los juegos de palabras, la mímesis analógica y el humor [que] llegan hasta el sarcasmo: en el teatro prevalecen los diálogos, el recurso de los géneros de la oralidad cotidiana; las protagonistas cuentan, platican, chismean, se chotean, se secretean, cuchichean ${ }^{8}$.

Reunidas ellas en este singular Tablero de tensiones, esperan impacientes la aparición de la premio Nobel, a quien todas admiran. Las "cultas damas", escritoras ellas que, como apunta Eduardo Mejía, ejercen el oficio más por búsqueda de una posición en la escala social que por auténtica convicción ${ }^{9}$, pasarán una peculiar velada en la lujosa suite con vista a la playa mexicana más glamorosa de la época que retrata. Mediante un juego belicoso de confesiones e indiscreciones en donde "se mezclan lo útil y lo agradable»", las mujeres escudrińan ociosas en la vida privada de la(s) anfitriona(s):

ESPERANZA: ¿Estás segura de que aquí no hay nada raro? Eunice: Naturalmente que sí. Matilde.

${ }^{6}$ J. Revueltas. «El cuadrante de la soledad», p. 410.

7 A. Rocco. "José Revueltas dramaturgo y guionista..., p. 12.

${ }^{8}$ L. Guerrero. "La obra oculta de Rosario Castellanos». Revista de Literatura Mexicana Contemporánea, año xv, vol. 42, núm. 16 (julio-septiembre de 2009), pp. 7-17.

9 R. Castellanos. «El eterno femenino», en E. Mejía (comp. y notas), Obras II. Poesía, teatro y ensayo, México: Fondo de Cultura Económica, 2014, pp. 363-454.

10 R. Castellanos. «Tablero de damas», en E. Mejía (comp. y notas), Obras II. Poesía, teatro y ensayo, México: Fondo de Cultura Económica, 2014, pp. 279-319. 
Patricia: Matilde no es rara: es poetisa.

ESPERANZA: ¿Y Victoria?

Aurora: Victoria es un monstruo.

ESPERANZA: ¿Y las relaciones entre ambas?

Eunice: (Con fruición.) ¿'Tú crees que son sospechosas? ${ }^{11}$.

La suspicacia de los ingeniosos comentarios cruzados de las asistentes deja entrever una cadena de relaciones hirientes, señales de fracasos, vocaciones truncas, soledades, logros medianos o hasta mediocres, necedades y aspiraciones inalcanzables.

Sin embargo, hacia el final de la pieza, la dependencia enfermiza de Victoria hacia su jefa muestra el tan guardado recelo por la indiferencia que ha sufrido por años: "Estoy segura -le dice a Matilde- que nunca me has mirado con más atención de lo que miras esa mesa» ${ }^{12}$. Matilde confiesa que el crecimiento de su profesión tan laureada la condujo al involuntario desapego del mundo, a la soledad y finalmente a su renuncia al amor: «Era como un río oscuro moviéndose dentro de mí. Y su rumor era el único que podía escuchar. Para lo demás estaba sorda. Todos empezaron a abandonarme. [...] Y aunque quisiera crispar las manos sobre lo que amaba, mis manos se abrían y dejaban escapar su presa» ${ }^{13}$.

Matilde reconoce al fin el amor silencioso que Victoria le ha profesado desde hace más de una década, que inclusive la llevó a abandonar sus propias aspiraciones de poeta: «iTanta abnegación, tanta ternura, tanto sacrificio equivocados! »» ${ }^{14}$ La actitud de dedicación y generosidad no fue desinteresada sino fincada en la búsqueda inútil de la correspondencia amorosa:

Matilde: [...] ¡Pobre Victoria! ¿Qué podría yo hacer para ayudarte?

Victoria: Nada. Ya tengo dinero de sobra.

Matilde: Pero tú no querías eso, querías algo que no he sabido darte.

Victoria: No hablemos más. Ya no tiene importancia ${ }^{15}$.

La secretaria decide renunciar a su trabajo, que efectuó al lado de su figura idílica, y abandona el exclusivo hotel con la intención de forjarse una nueva vida. Matilde se sabe cansada, algo enferma, vieja y sola, pero no aceptará la ayuda de la joven Aurora quien se ofrece a ocupar el puesto que ha quedado vacante, porque reconoce su forma egoísta, cuya única posibilidad es la de entablar una relación pragmática y fría, sin una auténtica correspondencia confidencial y, todavía menos, de naturaleza íntima.

11 Ibidem, p. 302.

12 Ibidem, p. 311.

13 Ibidem, p. 312.

14 Ibidem, p. 313.

15 Ibidem. 
Hacia el final de esta obra en tres actos, Matilde razona con serenidad: «Por lo menos procuremos no ser animales, tan humanos como para tropezar dos veces en la misma piedra» ${ }^{16}$.

Si bien la pieza de teatro fue silenciada en su época, se debió probablemente -le confesó Dolores Castro ${ }^{17}$ a Laura Guerrero- "porque ciertas poetisas reconocidas en el ámbito cultural mexicano se sintieron aludidas, y alguna hubo que buscó a la autora con pistola en mano para vengarse ${ }^{18}$.

También es de Rosario Castellanos la estudiada pieza El eterno femenino, de 1975. La obra está construida a partir de pasajes en donde intervienen personajes históricos (Maximiliano, Carlota o la Corregidora) que conviven con otros de tipo alegórico (Eva, Adán o la Serpiente) y algunos más que resultan comunes, propios de las clases media y baja, para proponer en sumatoria una visión de la condición femenina en México. Éste es el marco donde la estatua de sor Juana cobra vida y se le presenta a Lupita, la joven casadera, para hablarle de su contexto virreinal, y acusarse con rudeza por la vanidad, la pereza y la ignorancia.

Lo interesante en este pasaje es que la quinceañera Juana Inés, como simbólicos actos de vindicación, se corta el pelo y se trasviste hasta lograr, según reza la acotación, «un aspecto inequívoco de efebo, en el cual se complace» ${ }^{19}$.

Sin embargo, para efecto de este ensayo, no es menester detenerse en el travestismo ya resentido en alguna obra dramática de la poeta y dramaturga mexicana (Los empeños de una casa, por ejemplo, cuyo recurso es tan propio de la comedia española de su época) y referido también en este otro texto de Castellanos. Lo que sí vale destacar es el atrevido diálogo que bajo una fórmula metateatral Juana entabla con Celia, mientras sostienen movimientos acompasados y armoniosos tramando entre las dos una danza de matices sensuales de gran elocuencia:

Celia: Fortuna es

tenerte entre las sábanas,

y sacrificar a Venus

hasta que la luz del alba

viene a darnos una tregua

... o a establecer más batalla.

JUANA: ¿Y me trocarías por otro?

Celia: ¿Se trueca el oro por plata?

16 Ibidem, p. 318.

${ }^{17}$ Dolores Castro (1923) es ensayista, narradora y poeta mexicana, en cuya obra «aborda el tema amoroso con gran diversidad de matices, va del amor fraterno al erotismo sutil; también es un canto a la desolación, a la muerte y al dolor compartido». A. Ocampo. Diccionario de escritores mexicanos, tomo I A-Ch. México: UNAM, 1988.

${ }^{18}$ L. Guerrero. La ironía en la obra temprana de Rosario Castellanos. México: Universidad Iberoamericana/Eón, 2005.

19 R. Castellanos. «El eterno femenino», pp. 363-454. 
¿Se cambia el rumbo del astro?

¿Vuelve la flecha a su aljaba?20

Es evidente y perfectamente logrado el tono erótico de estos versos. Elogian la posibilidad dispuesta a mano de un cuerpo femenino complementario en la larga noche de amor que ya se advierte; y más aún: este lance amatorio puede continuar con el día ya amanecido, si es que la necesidad persiste.

Después de un intenso crecimiento dramático de la escena, viene enseguida la represión de los cuerpos que deben renunciar a su deseo; el clamor para que la muerte llegue no como un castigo a la acción réproba ante el ojo común y castigador, sino por la inevitable despedida de la mocedad:

Juana: [...] Adiós, adiós juventud,

adiós atmósfera clara

de la música y los números,

de la amistad conversada,

adiós a lo que no fui,

a lo que fui y me sobraba ${ }^{21}$.

Luego de contemplarse ambas -Celia y Juana- por un momento, la frágil esfera poética se despedaza con un tosco rompimiento que da lugar a la reflexión donde Juana sostiene una breve conversación con Lupita, la chica que está a punto de casarse. La novia, conmovida por el momento definitivo de su boda, que ya se prepara, pregunta acerca de la (im)posibilidad, y los límites o alcances del amor auténtico; Juana con su lucidez característica le refiere no solo el impedimento del amor sáfico que acaba de quebrarse sino por extensión entiende que toda idea de amor es insostenible y que llegado el momento, hay lugar solamente al acto reproductivo básico: «JuANA.- En principio, todo amor es imposible: una idea obsesiva que se apodera de los espíritus solitarios. Los demás no se enamoran: se ayuntan ${ }^{22}$.

En el drama de Castellanos las amantes preparan la consumación del acto sexual de una forma tan ardiente como intensa, razón que podría colocar a la «real» monja mexicana como de filiación homoerótica pero cuyo intríngulis rebasa las intenciones de este trabajo. Lo destacado, en todo caso, es que «desde el siglo pasado en que se le reivindicó [en México a sor Juana] junto con todo el barroco, sus poemas se han leído como fundacionales y paradigmáticos del lesbianismo» ${ }^{23}$.

En la obra de Rosario Castellanos, como se ha visto, no hay espacio para la ambigüedad, pues Celia reclama ardientemente mientras Juana duda por momentos entre la huida y la entrega corporal, decidiéndose finalmente por el sitio «Adonde

20 Ibidem, p. 405.

${ }^{21}$ Ibidem, p. 406

22 Ibidem.

${ }^{23}$ S. TÉllez-Pons. La sintesis rara de un siglo loco. México: Fondo Editorial Tierra Adentro, 2017. 
es / la inteligencia soledad en llamas $»^{24}$, inclinándose en consecuencia hacia el entendimiento y la razón aunque su propio cuerpo sea un fuego que incendia. En su elección por el estudio, la monja mexicana sacrifica el desfogue vital de su sexo.

\section{MANIFESTACIONES SÁFICAS A FINES DEL SIGLO PASADO}

Será hasta las décadas de los setenta y los ochenta del siglo veinte cuando se muestran amplias y decididas recurrencias, frecuencias y variedad en los tratamientos de la sexualidad diversa en la dramaturgia mexicana, pero éstos serán mayoritariamente de manifestaciones eróticas y de travestismo entre los varones.

Es a nuestro comprender que las piezas de Hugo Argüelles (1932-2000) son punteras en vista de la violencia exacerbada, ya implícita o explícita, que propone en su carpeta dramática. En sus piezas aflora el humor impertinente, la ocurrencia anecdótica, los inusitados giros dramáticos y el desbocamiento de conductas lamentables que expresan el lado oscuro, impío e hipócrita de la sociedad mexicana. Este autor estuvo interesado en el escrutinio de personajes masculinos homoeróticos con obras como, por ejemplo, Los gallos salvajes o Escarabajos, o bien apartándose más todavía del realismo en El cocodrilo solitario del panteón rococó, donde hace una rápida alusión al convivio lésbico de dos personajes que celebran su descubrimiento sexual y toman venganza contra el hombre socarrón que las comparte:

Solveig: [...] ¡Cómo será, que hasta ya prefiero dormir contigo!

Rosamunda: Por mí... no te agüites.

Solveig: (Sorprendida.) ¿No te disgusta?

Rosamunda: Si me disgustara, no te hubiera dejado. Lo que pasa es que yo creo que ya me está gustando todo.

Solveig: Nos estamos volviendo reterraras con esta clase de vida, ¿`verdad?25

Como puede advertirse, los personajes actúan desenfadados, se expresan con soltura y disfrutan sin tapujos del intercambio sexual entre ellas, que les permite gozar de la libertad de sus preferencias.

Por otro lado, menciona Vicente Leñero la irrupción en la escena de toda una generación de autores que abrirían el abanico de posibilidades expresivas: «A finales de los ańos setenta y principios de los ochenta, en una época en que el espectáculo del teatro presuponía una alternativa frente a una dramaturgia supuestamente agotada, en plena polémica de directores contra dramaturgos [...], surgió en México una

${ }^{24}$ R. Castellanos. El eterno femenino, p. 406.

${ }^{25}$ H. Argüelles. El cocodrilo solitario del panteón rococó, en Obras premiadas II, México: UNAM, 1995, pp. 13-106. 
generación de autores dramáticos a quienes se agrupó bajo un membrete cómodo, pero convencional: Nueva Dramaturgia Mexicana»"${ }^{26}$.

Se trató del lanzamiento editorial y escénico de un amplio número de jóvenes escritores procedentes de diversos talleres y formaciones que hicieron uso de un lenguaje fresco, algunos con la influencia dinámica del cine mediante cortes anecdóticos, espaciales o temporales, y la trepidante evolución de la trama. Con sus tratamientos casi siempre violentos, hicieron también uso de temáticas de variaciones sexuales, ya como una referencia de fondo o como centro de su exposición. Este grupo, conformado más por dramaturgos que por dramaturgas, abordó el tópico homoerótico entre varones, siempre cargado de violencia y situaciones limítrofes que incluso solo se resuelven en muchos de los casos con el asesinato.

Perteneció a esta generación Óscar Liera (1946-1990), seudónimo de Jesús Cabanillas Flores, quien escribió celebrados dramas como Dulces compañias, cuya trama tiene lugar en unos departamentos contiguos de la ciudad, en los que hace su aparición el chichifo que asesina a dos incautos clientes, un hombre mayor y una mujer, que lo han ligado en dos distintas ocasiones en la calle. Liera es autor también de una breve pieza, Los camaleones, que coloca el lesbianismo de la protagonista como un tema no resuelto con su familia. Laura, en la soledad de su apartamento, ensaya la declaración que quisiera hacer a su padre, decirle que siempre le han gustado las mujeres, que como un camaleón ella se ha vuelto mimética jugando roles que no le agradan, que ha roto hace una semana con su chica... De la facilidad de palabra pasa al sarcasmo, se burla de la heteronormatividad y de sus ceremoniales que concluyen con el sometimiento de la mujer por parte del macho:

Asquerosamente penetrada por un hombre, con un sexo extraño al de ella, un sexo que ni siquiera se le asemeja, un falo vomitante y duro como un hierro que sin piel rompe membranas y se va introduciendo sin clemencia entre las carnes más blandas y el macho ruge de placer, el macho posee «su cosa» y casi la estrangula con sus gritos y su baba. Y cuando el naciente gozo de la mujer aparece, el macho canta triunfal su himno eyaculatorio, se limpia la boca y se voltea de nalgas ${ }^{27}$.

Años más tarde, la escritora Gilda Salinas (1949) experimentará en su escritura con el tema lésbico y los impedimentos para la solución afortunada de las protagonistas. En su obra Primera mudanza marca el seńalamiento acusatorio de la madre de una de ellas que reacciona violentamente al enfrentarse a las preferencias de su hija: «Yo estaba cenando, llegó por detrás, me jaló el pelo y sin darme tiempo a nada dijo que dónde había dejado a mi media tortilla, que qué bonito, que nada

${ }^{26}$ V. LeÑERo. «Introducción», en La nueva dramaturgia mexicana, México: Ediciones El Milagro/CNCA, 1996, pp. 9-39.

27 Ó. Liera. Los camaleones, en La Piña y la Manzana. Viejos juegos en la dramática, México: UNAM, 1982, pp. 37-43. 
más eso le faltaba: una manflora en la familia, pero que de su cuenta corría quitarme esas cochinadas de la cabeza [...] $\aleph^{28}$.

Lilia, la chica, trae a cuenta el conflicto generacional muy explicitado en los tópicos de la mencionada «Nueva Dramaturgia», al marcar un abismo en cuanto a intereses dispares y posturas vitales de los personajes. La rebeldía se considera aquí como un acto reprobable por parte de los progenitores. Se trata a su vez de acciones de autodefinición por parte de las jóvenes a quienes se les considera desordenadas y hasta disolutas cuando entran en pugna con sus familiares por las elecciones de orden sexual.

La Primera mudanza muestra el lado hostil que las jóvenes tienen que afrontar para llevar a cabo el proyecto de vida en pareja. Lilia expresa la urgencia por literalmente huir de la ciudad de México y estar lejos de la influencia de la madre, a quien se refiere con temor. Sin embargo, con este recelo manifiesto hacia la progenitora, se advierte que toda aspiración estará condenada al fracaso, puesto que la urgencia tan necesaria de cambiarse de lugar para vivir difícilmente solidifica un plan adecuado. Por eso Lilia intenta convencer a Isa para que abandone la Universidad a pesar de que fue tan difícil su ingreso.

En esta pieza de Salinas, la joven pareja repite modelos de imposición aprendidos del contexto machista que las rodea y los hace elocuentes, como cuando Lilia le recrimina a Isa su forma de comportamiento: «Me choca que no me digas las cosas, eres como los hombres, igual que mi papi, puras mentiras para taparle los cuernos a la Gorda $»^{29}$; y más adelante, ofendida le confiesa: «... a lo mejor tú eres como los hombres, nada más querías cogerme y ya ${ }^{30}$.

En la radio se escucha la melodía Amor probibido interpretada por Selena y su grupo Los Dinos, convirtiéndose en una marca del señalamiento inculpador hacia el acto sáfico y la reacción intrépida de sus aludidas.

Luego de pasar la noche juntas, el día siguiente, que se aventura como el inicio de esta nueva vida, la madre de Lilia aparece en el cuarto de azotea, lanzando ofensas y provocaciones a la joven pareja. La violencia verbal y hasta física le impide a su hija llevar a cabo su objetivo de partir a Veracruz. A rastras se la llevan con la advertencia cruel que la señora dirige a Isa, quien sorprendida ve la escena: «iY no se te ocurra buscarla, manflora asquerosa, porque juro que te hago pedazos con mis propias manos! $\aleph^{31}$. Esta intromisión, empero, permite a Isa recuperar la ruta de su vida estudiantil y apresurarse para tener un exitoso cierre de semestre.

En un vuelco con respecto al tratamiento del lesbianismo en el teatro, Inseminación artificial de Tomás Urtusástegui (1933), como su nombre precisa, hace referencia al proceso de concepción a partir de un donante. Beatriz y Luisa celebran toda vez que el médico les ha confirmado su embarazo. Ellas son dos mujeres pro-

28 G. Salinas. Primera mudanza, en Más teatro gay, México: Pax, 2002, pp. 103-124.

${ }^{29}$ Ibidem, p. 110.

30 Ibidem, p. 114.

31 Ibidem, p. 123. 
fesionistas, sensatas y determinadas a llevar a cabo su objetivo de vida en pareja que con orgullo ostentan, y que se advierte por ejemplo en el dicho de Beatriz al final de la breve pieza dramática: "Me vale una y dos con sal que las leyes mexicanas no permitan el matrimonio entre mujeres ${ }^{32}$.

Tanto esta última obra como la de Gilda Salinas fueron publicadas en volúmenes distintos en el mismo año de 2002. Esta acción editorial marcó clara postura política en torno a la discusión que en aquellos momentos se vivía desde el esquema legislativo del país: Editorial Pax México publicaba sus dos volúmenes Teatro gay y Más teatro gay marcando de esta forma un hito en la historia mexicana de las dramaturgias homoeróticas. En su prólogo, titulado «El teatro sale el clóset», el propio Urtusástegui señala con certeza que después de algunas obra de Salvador Novo y Xavier Villaurrutia ${ }^{33}$, el «armario» se abrió definitivamente a partir de la segunda mitad del siglo pasado, ya que «jamás de los jamases, un homosexual podía ser protagonista, y menos aún, un personaje heroico. Eso en cuanto al personaje gay, [ya que] las lesbianas no aparecían ni aun en esos roles secundarios; ni para reír de ellas ni para despreciarlas; sencillamente no existían $»^{34}$.

\subsection{SELENA, LA REINA DEL TEX-MEX}

Como sucede con Victoria en Tablero de damas de Rosario Castellanos, la secreta devoción que invita a trazar una directa cercanía con la amada mediante la práctica servil va a encontrarse también en el texto dramático Selena, la reina del tex-mex (1999) de Hugo Salcedo (1964), y que retoma el suceso acerca de la popular cantante asesinada a quemarropa en 1995 en la ciudad texana de Corpus Christi, por Yolanda Saldívar, quien primero fuera la presidenta del club de admiradoras y después su acompañante personal.

Durante el convivio laboral y cotidiano que ambas mujeres acuerdan (Selena de 23 ańos y Yolanda de 35), la asistenta va agrandando el aprecio por Selena, quien a su vez la llega a considerar como una segunda figura materna, manera que usará también cuando se dirija a ella de forma cariñosa. La intimidad de ambas, en apariencia escondida, se descubre abiertamente cuando -en la ficción- el padre de la cantante (Abraham Quintanilla) estalla furioso porque su hija se niega a presentarse en uno de los conciertos musicales acordados:

Yolanda: Si me permite, señor Quintanilla [...].

Abraham: A ti nadie te permite dar opiniones.

Selena: Yo sí lo permito. Es mi asistenta y tiene todo el derecho.

32 T. Urtusástegui. Inseminación artificial, en VV. AA., Teatro gay, México: Pax, 2002, pp. 79-90.

33 Se refiere a El tercer Fausto (1934) de Novo (1904-1974) e Invitación a la muerte (1944) de Villaurrutia (1903-1950).

${ }^{34}$ T. Urtusástegui. «Prólogo. El teatro sale del clóset», en VV. AA., Teatro gay, p. vi. 
Aвraнам: ¡Y la defiendes, desvergonzada! ¡Contranaturales! Y yo que imaginaba este tipo de maldición pero lejos, en otras familias menos decorosas. Y resulta que el mal está más cerca de lo que creo. [...] Llegaste a corromper con tu cáncer a mi hija. Me la cambiaste, no es la misma, y ahora quisiera desconocerla [... ${ }^{35}$.

De este pasaje se desprenden varias cuestiones que resumen la hostilidad del trato familiar cuya auténtica relación está fincada solo en tanto es parte de un acto mercantil o comercial, y el ambiente demarcado por la postura agresiva, de tradición machista y heteronormativa del sistema que se representa en el padre. En un primer momento él excluye a Yolanda por ser una empleada y no parte de la familia; pero cuando Selena pretende darle voz, Abraham define a ambas como practicantes del "pecado nefando" y "contranatural» que va a entender como un castigo para él y su estirpe. No es que el padre no supiera de la existencia de esta práctica, sino que en su posición de macho-varón y cabeza de familia, prefería dirigir su mirada hacia otro punto, más preocupado quizá por los dividendos económicos que por las elecciones de tipo sexual de la hija.

Ante la actitud desobediente, el lesbianismo será entonces considerado por el progenitor como una perversión o enfermedad de contagio. En su examen, Yolanda llegó para transmitir su fetidez y a corromper la castidad de su hija. Esta consideración -aunada a la acusación de robo y malos manejos publicitarios- será determinante para apoyar el desenlace funesto que bien se refleja en la obra. Hacia el final de la pieza, en el interior de la habitación 158 del Days Inn, Selena y Yolanda sostienen una conversación sincera y tirante, que prevé ya el rompimiento definitivo: «Selena: No te enojes, madre. Lo que menos quiero es que te enojes conmigo. Tú me enseńaste las cosas más bonitas de la vida. [...] Te necesito. Tú entiendes a lo que me refiero" ${ }^{36}$.

Esa dependencia permite que la cantante se dibuje como un personaje de endeble carácter y un tanto enfermiza, razón por la que pudo ser de fácil manipulación primero por su propio padre y después por su representante. Entre ellas se ha establecido la fórmula de una comunicación indirecta que debe apreciarse entre líneas como un código particular y secreto. La fórmula dramatúrgica apoyada en el hecho de no decirlo todo, no explicitarlo completamente o no revelar de forma directa la información privilegia la cimentación del suspenso a partir del subtexto que apela a estrategias de interpretación infinitas; lo no dicho del discurso, dice Anne Ubersfeld, es lo que condiciona y revela la posición de los personajes en la trama, abriendo la expectativa en el espectador hacia «el inventario de lo propuesto» $^{37}$.

Es, sin embargo, este tipo de forma conversacional en Selena lo que coloca a sus interlocutoras como víctimas de un estado social discriminatorio, pues, aun

${ }^{35}$ H. Salcedo. Selena, la reina del tex-mex», México: Universidad Autónoma de Nuevo León, 1999.

${ }^{36}$ H. Salcedo. Selena... p. 24.

37 A. Ubersfeld. Semiótica teatral. Madrid: Cátedra/Universidad de Murcia, 1989. 
en la más privada instancia, ellas deben mantener la obligada moderación de sus formas de comunicarse.

Ambos personajes son la parte complementaria de una relación viciada de protectora-protegida que, como se decía antes, resulta no ya solo una sospecha sino la confirmación de los comportamientos «indecentes» que les echa en cara el propio padre. Cuando la intérprete sutilmente enfrenta a su protectora para reclamarle las compras a escondidas de artículos de lujo para su uso personal, ésta reacciona indignada; pero Selena, más noble, intenta componer la situación: «Yo sé cómo contentarte», le dice. Y como una muestra de complicidad entre ambas declara: «Nosotras somos distintas. Qué importan las cosas que dice mi papá [...]» ${ }^{38}$. Sin embargo, Yolanda, quien se sabe descubierta y cercada, determina asesinar a tiros allí mismo a su propio ídolo.

Amor prohibido, que también sería uno de los auténticos éxitos musicales de Selena y su conjunto musical en los años noventa, es la melodía que lejanamente se deja escuchar en la escena del crimen perpetrado: "Amor prohibido murmuran por las calles / Porque somos de distintas sociedades/Amor prohibido nos dice todo el mundo...» ${ }^{39}$.

\section{EL TEMA SÁFICO EN EL SIGLO VEINTIUNO}

La narradora y dramaturga Gabriela Ynclán (1948) fue alumna de Hugo Argüelles en sus talleres de composición. Ella ha escrito interesada en demarcar la función de la mujer en la sociedad mexicana para exponer su rostro hipócrita y machista. Ynclán da voz a los marginados exponiendo "con verdad, honestidad y decoro la diversidad de género y la diversidad sexual ${ }^{40}$. Esta autora, en cuya obra resuenan los ecos de la producción literaria de otras mexicanas como Inés Arredondo o Elena Garro, arma historias de violencia contra las mujeres y esquemas de impunidad y colusión entre las fuerzas de poder.

Aunque en su obra Casa de adobe el tema central es el narcotráfico como un padecimiento resentido y enquistado en este tiempo mexicano, hay en el texto «amores de fondo incestuoso, intolerancia machista y lésbica» ${ }^{41}$. El mundo de la cultura purépecha se presenta no solamente con la expresión en su lengua, a la que aluden algunos de sus personajes, sino también con arraigo hacia las creencias y costumbres de ese pueblo mexicano. En el contexto de intimidación y zozobra, Concha y Julia se expresan sus mutuas predilecciones conscientes de que esas prácticas deben ser guardadas como un secreto.

38 H. SAlcedo. Selena..., p. 24.

39 S. Quintanilla-PÉrez. Amor prohibido (2 de febrero de 2012). https://www.youtube. com/watch?v=dvfZ95ueOcQ. Consultado el 30/06/2017.

40 G. ValdÉs Medellín. «Prólogo. Gabriela Ynclán: En el corazón mismo de nuestras raigambres», en Mujeres de tierra y fuego, México, Ariadna, 2016, pp. 9-14.

${ }^{41}$ Ibidem, p. 14. 
De igual manera y como se ha señalado, a la secrecía que es resultado de la acción que se advierte como pecaminosa se suma aquí el intento de escape del esquema agobiante, pendenciero y machista. Se presiente la posibilidad de un cambio si se alcanza a realizar el atrevimiento de la huida: «JulIA: [...]. Vámonos, chiquita, yo también puedo darte muchas cosas y sin riesgos. Te juro que no vas a extrañar nada, nada» ${ }^{42}$.

En esta obra, sin embargo, el deseo de las mujeres va a ser descubierto por el prometido de una de ellas y a su vez hermano de la otra. El varón se siente ofendido por partida triple, tanto por el engaño propiamente como por la razón de que éste se realice en el cuerpo de una mujer, y que a su vez ella sea de su propia familia: «iSi me ibas a cambiar lo hubieras hecho por otro cabrón, bien macho, no por mi hermanita!» ${ }^{43}$.

Como producto del nivel de tensión que se ha edificado, esta pieza no puede concluir sino con un final trágico en medio de toda la confusión del descubrimiento lésbico, y en contraste enmarcado por la celebración que se lleva a cabo en el pueblo. El ruido de los cohetones va a confundirse con el disparo que proviene de la casa de adobe y que acabará con la vida del ofendido Boni.

Para cerrar esta parte, se indica la respuesta creativa a los señalamientos acusatorios para los/las practicantes de la sexualidad diversa. Artistas como Jesusa Rodríguez (1955) y Liliana Felipe (1954) van a desplegar su ingenio mordaz y originalidad de forma hilarante, subversiva y con un agradecible descaro en numerosos espectáculos de cabaret.

La dupla Rodríguez-Felipe entró también con el apoyo de recursos del performance a las cuestiones referentes a las diversidades y predilecciones sexuales. En 2001, por ejemplo, en plena discusión de la Ley llamada como Sociedad en Convivencia en el antes Distrito Federal e impulsada por la diputada y activista Enoé Uranga, estas artistas, que forman pareja en la vida real, decidieron "casarse» públicamente en una acción celebrada en plena calle frente al Palacio de Bellas Artes en el centro de la ciudad de México, y secundada por otras treinta parejas homosexuales que realizaron allí sus respectivos contratos civiles.

Con este acto, Jesusa y Liliana se hacían solidarias a las decisiones de las y los contrayentes, pero a su vez realizaban mofa de la imposición o «legitimidad» promulgada por la Iglesia católica vaticana. Al respecto, Jesusa Rodríguez declaró de forma irónica en una entrevista: «Es evidente que nuestra relación ha sido siempre tan pública que casarnos era un acto nada más de cumplir moralmente con la religión católica porque nos sentíamos en pecado» ${ }^{44}$.

Con la utilización de estrategias performativas afincadas en la disidencia política antiasimilacionista y la crítica a la ideología religiosa enajenante, se realizan

${ }^{42}$ G. Ynclán. Casa de adobe, en Mujeres de tierra y fuego, pp. 75-102.

43 Ibidem, p. 101.

${ }^{44}$ M. Ramírez-Cancio y C. Crosby. Entrevista a Jesusa Rodríguez y Liliana Felipe (23 de agosto de 2001). http://hemisphericinstitute.org/hemi/es/hidvl-profiles/item/1598-habito-int-jesusa-lili. Consultado el 28/09/2015. 
confrontaciones públicas como eficaz alegato acusatorio que plantean un estrecho contacto con el observador que a veces hace también de participante. Ya no será suficiente entonces, como menciona Leticia Sabsay, «mostrar la diversidad sexual cultural si la misma no es capaz de intervenir y cuestionar las estrategias fundamentales en las que esa epistemología se sustenta ${ }^{45}$.

Por la naturaleza de su complejidad representacional y el atractivo esquema de exposición, la performance va a ser un camino idóneo para manifestar no solamente ya asuntos de género, sino que también será un catálogo vivo de las modalidades sexuales divergentes.

\subsection{Guiochíns, Escalante, Berman}

Otras estrategias dramatúrgicas con referencia lésbica en el teatro mexicano, y quizá más afortunadas en cuanto a la concepción, el tratamiento y las resoluciones textuales, son las que se advierten en algunas piezas que aparecieron ya entrado el siglo veintiuno y que fueron escritas por mujeres. Conocedoras ellas de la naturaleza femenina al escribir desde sus propias condiciones (y en alguno de los casos, diríamos hasta convicciones), las plumas de Elena Guiochíns (1969), Ximena Escalante (1964) y Sabina Berman (1955) han demostrado solvencia y cualidades dramáticas de importancia.

De la primera de este grupo, hay una pieza que tuvo éxito notable durante su estancia en el escenario. Bellas atroces de Guiochíns es una obra que tiene -al menos- dos ediciones distintas: la primera de 2002 y la segunda revisada por su autora en 2011 pero publicada en 2014. Según Antoine Rodríguez: «Es una obra escrita desde una postura asumida como lésbica que pone en escena las relaciones lésbicas de tres personajes mujeres cuyos nombres remiten a un subtexto cultural católico (Eva, María, Lilith) y una mujer que las observa» ${ }^{46}$.

La obra abreva de la tradición cultural y literaria para proponer una serie de cuadros que muestran la amistad romántica y el ejercicio del amor entre féminas, en un trayecto temporal que cubre, a saltos, desde la época victoriana del siglo diecinueve hasta fechas más cercanas. Vale mencionar que aquel periodo, marcado por la consolidación del poder colonial y la industrialización de Inglaterra, demarcó la defensa del puritanismo, el moralismo y la disciplina que condujo a férreos castigos para los insubordinados, como se aprecia - por ejemplo- en la condena por sodomía que llevó a Wilde a dos años de trabajos forzados. En contrapartida, aunque las mujeres no tenían cabal derecho al sufragio, sí ganaron el derecho a la propiedad después del matrimonio, el derecho a divorciarse y el derecho a luchar por

45 L. Sabsay. «IV. Políticas queer, ciudadanías sexuales y decolonización», en D. Falconí Trávez, S. Castellanos y M.A. Viteri (eds.). Resentir lo queer en América Latina: diálogos desde/con el Sur, Barcelona-Madrid: Egales, 2014, pp. 45-58.

46 A. Rodríguez. «Indecentes y disidentes obras queer de teatro latinoamericano». Tramoya, vol. 120, (2014), pp. 5-12. 
la custodia de los hijos tras la separación con sus maridos; época de contrastes, de hipocresía y doble moral: del desarrollo de un mundo subterráneo como frecuente mercado de sexo, los fumaderos de opio y la explotación infantil.

Guiochíns, la autora, define con puntualidad su ejercicio en el prólogo que hace acompañar su texto dramático en la edición de 2002: «Bellas Atroces aborda [...] las actitudes acerca de la sexualidad que iniciaron el proceso de cambio. Las convicciones sexuales han tomado a lo largo de la historia como punto de referencia una doble moral partiendo de la supremacía del hombre como principio fundamental $»^{47}$. Y más adelante: «Bellas Atroces ofrece una peculiar interpretación de la identidad e imagen femenina; aquel tipo de mujer que tanto inquieta a la sociedad, en oposición a la mujer natural (esposa-madre)» ${ }^{48}$.

Esta visión binaria y polarizada de la mujer se alimenta también de la fantasía de corte mitológico que incorpora tres personajes que permiten la visualización de la pulsación sexual femenina mediante los roles que las identifican: Eva, la mujer creada o derivada de la figura masculina de Adán, y a su vez la mujer que ha sucumbido a la tentación y que mediante esta falla arrastrará a su pareja y a toda la progenie a la vida mortal; María, la inmaculada virgen por excelencia y elegida para ser la madre del hijo de Dios; y Lilith, la insumisa y primera rebelde. Ellas, dice Guiochíns, «encarnan los orígenes y circunstancias de estos sentimientos -orígenes de la sexofobia- en una trama de emociones contradictorias y polarizadas que oscilan entre la fascinación y el aborrecimiento, entre la atracción sexual y el pánico al abismo» ${ }^{49}$.

En el principio de esta pieza se muestra a dos mujeres que bailan (Eva y María) marcando con la música el compás que se hará presente en todo el texto: evoluciones de los personajes, el mutuo acompañamiento, el ritmo, la exposición pausada pero continua de mujeres que hablan de mujeres en un tiempo actual donde hacerlo es estar a la moda, estar in, ya que se trata de hacer uso y a la vez ser parte del dilatado proyecto de amenidades de la mercadotecnia como las barras de programas en televisión, las revistas dirigidas a las lectoras, los ciclos académicos y culturales que las incluyen de manera privilegiada, los talk shows, etcétera. En la obra se marca la paradoja de que ante tantos espacios de visibilidad, las mujeres tienen que seguir haciendo inaudibles sus preferencias sexuales e invisibles sus acciones íntimas.

El recorrido histórico de la condición lésbica se expone en la pieza mediante el texto pronunciado pero también encarnando a otras mujeres como a la excéntrica poeta estadounidense Emily Dickinson o su propia cuñada, la esposa de su hermano mayor, con quien ella tuvo una relación profunda y confidente. Se da presencia también a las inglesas Vita Sackville-West, «la honorable señora Nicolson», abiertamente bisexual, y Virginia Woolf (Adeline Virgine Stephen), que fueron integrantes del reconocido grupo de Bloomsbury y quienes sostuvieron un romance real que decantó hacia la escritura:

\footnotetext{
47 E. Guiochíns. Bellas atroces. México: Anónimo Drama, 2002.

48 Ibidem, p. 5.

49 Ibidem, p. 8.
} 
María-Virginia: «Son los trajes los que nos usan, y no nosotros los que usamos los trajes», Vita querida.

Eva-Vita: «Los trajes siguen siendo varones o mujeres», y yo soy tu Orlando, Virginia mía ${ }^{50}$.

En la escena intitulada «Boston Marriage», se da razón del significado de este término que fue utilizado en Nueva Inglaterra, EE.UU., para describir una relación monóga ma y duradera entre dos mujeres respetables, financieramente independientes o con estudios profesionales, que no se habían casado. Mujeres con perfiles feministas, autosuficientes y emancipadas que entre ambas construyen poderosos vínculos emocionales y que podían -por supuesto-incluir la práctica sexual:

LA INviTADA: Matrimonio bostoniano: mujeres profesionales que no tenían necesidad de un marido.

María: Pero sí gran necesidad de una esposa.

Lilith: Una necesidad mutua ${ }^{51}$.

A merced de la consideración de los rondines históricos como el que esta pieza propone y la consideración de las teorías feministas, el siglo veinte exhibe la presencia de la postura feminista y su exposición extendida: los usos y alcances del «disfraz» performativo estudiado por J. Butler y las abiertas formas de sexualidad entre las mujeres. Ellas, como personajes, colocan disfraz sobre disfraz y complejizan sus relaciones interpersonales marcando por un lado un esquema de liberación, pero a la vez una pérdida de identidad donde el terror moderno y poderoso va a ser la sexualidad practicada entre mujeres: «Eva: No me gusta que me guste una mujer que se disfraza de hombre. [...]. Cambió mi percepción del mundo. Ahora la fiesta de disfraces está allá afuera» ${ }^{52}$.

La sociedad heteronormativa insiste en marcar con su dedo inquisidor las prácticas descentradas. Desde el otro lado de la interlocución, complementaria a la persistencia de Liera en Los camaleones, Eva (en el rol de madre) va a quejarse del comportamiento de su hija y aprovecha para mostrar el repudio hacia la configuración masculina de su hija:

Mi hija es extraña. No la entiendo, nunca ha tenido novio, vive sola y siempre sale con amigas. Me intrigan pero no me gustan. Mi hija es una pesadilla [...]. No la conozco. Me saca de quicio. La admiro y la detesto al mismo tiempo. Admiro su independencia, envidio su libertad, aborrezco su corte de pelo, su indumentaria posmoderna, sus ademanes de macho ${ }^{53}$.

50 E. Guiochíns. Bellas atroces. Tramoya, vol. 120 (2014), pp. 77-108.

${ }^{51}$ Ibidem, pp. 86-87.

52 Ibidem, p. 91.

53 Ibidem, p. 89. 
La práctica sáfica no podrá aquí desprenderse del prejuicio de «inversión abyecta» o «trastorno» como la consideró en 1869 el psiquiatra alemán Carl von Westphal, etiquetando de «asexuales» $\mathbf{O}$ «semi-mujeres» a quienes desprecian la domesticación, considerándolas inclusive como «una amenaza potencial para el orden social» ${ }^{54}$.

Al igual que en algunos tratamientos homoeróticos de los varones en la dramaturgia mexicana, la "salida del clóset» va a ser triunfal, digna de celebración en donde aparecen juegos de palabras ingeniosas y ocurrentes como cuando Lilith invita a María al festejo: "Alesbiánate, mujer», le grita. Y más adelante, sardónica, le pregunta por la invitada que acaba de entrar al baño: «¿Así que ese es tu clítoris platónico?, ${ }^{55}$.

Por su parte, la escritora Ximena Escalante muestra su interés reflexionando en torno a los procesos de creación y la escritura, el metadiscurso y los juegos de probabilidades dispuestos en el teatro. Ha escrito algunas de sus piezas considerando como personajes a figuras de la literatura, la ficción literaria, el mundo del teatro y el espectáculo. En el corpus de su obra hay muestra de interés por la figura de la notable escritora, periodista y actriz Sidonie-Gabrielle Colette (1873-1954), quizá en parte debido a sus deterioradas condiciones de trabajo, que le fueron impuestas y que la dramaturga misma señala:

Colette fue obligada a escribir, encerrada en un cuarto en el que, según ella misma relata, solo había una mesa, una silla, un cuaderno y un lápiz. Su marido cerraba con llave la cárcel creativa por horas, hasta conseguir un material interesante. Ella descubrió que sus aventuras en la escuela secundaria podrían ser ese buen material, y las aventuras de Claudine le dieron mucho más que fama: una crisis de ceguera que determinó su identidad como escritora. El marido opresor y la soledad obligada permitieron a Colette conocer la escritura, su más fiel compañía a lo largo de una vida exaltada y caótica ${ }^{56}$.

La ficción se construye a partir del flash back que se coloca al inicio la obra: Colette, siendo ya anciana, atiende un elegante salón de belleza que le permite de esta manera combinar la sofisticación y la confección de apariencias, acaso como parte de una teatralidad de la que no quiere desprenderse, pero sobre todo para sobrevivir económicamente luego de su retiro de la farándula. A merced de la visita de una clienta y mientras prepara los tintes para el pelo, ella recupera paisajes de su memoria que se van corporeizando mientras trabaja.

En Colette, la pieza de Escalante, van a estar, ya presentidos o explícitos, los tópicos de la sexualidad, el erotismo y la perversión como directa alusión a las circunstancias que rodearon la vida de la escritora con Willy (Henry Gautier-Villars), su marido, y el mundo del teatro de la belle époque que vivieron. La traza vital solo

${ }^{54}$ Ibidem, p. 93.

55 Ibidem, p. 99.

56 X. Escalante. Colette, en Encierro, pasión y desesperación, México: El Milagro/UANL/ CONACULTA, 2013, pp. 21-99. 
se va a entender a partir de la experiencia del sexo de los personajes, los intercambios de parejas, el voyerismo, la sodomía, y aun con todo ello la insatisfacción de la carne, como expresa con fastidio Colette a alguno de sus actores-amantes mientras lo rechaza, o cuando reclama a Willy, quien solamente la escucha sin articular palabra:

Colette: No sé quién soy en tu vida, no sé qué hago aquí ni por qué hago por ti todo lo que hago. [...]. Me usas. Me explotas. Me exprimes. [...] ... no soporto cuando estamos solos, se siente todo tan...

WILLY: ...

Colette: ... Como...

WILLY: ...

Colette: ... Tan vacío ${ }^{57}$.

Este sentimiento de banalidad recurrente es el que empuja a la protagonista para que busque satisfacción en otras fórmulas sexuales que le proporcionen un sentido de realización a su vida. Quizá por eso mismo su apertura hacia la práctica sexual lésbica que cumple sin apuro, como cuando es invitada a enrolarse en un nuevo proyecto que combina el arte del mimo, la actuación y la acrobacia:

Colette: Me gustan tus ideas.

Mujer: Sí, te gustan.

Colette: ... Tienen sentido...

Mujer: ... Me gustan tus labios...

Colette: ... Tienen...

Mujer: ... Besos...

Colette: ... Ajá...

Mujer: ... Esperándome...

Colette: ...

(La Mujer la besa.) ... (Se deja.)

Mujer: ... Y me gusta tu cuerpo...58.

El intercambio dialógico a partir de conversaciones de tan breve extensión puntualiza e intensifica la situación dramática; dinamiza la acción y provoca el crecimiento de expectativa. El afán de las mujeres se expresa mediante el mínimo de voces apenas susurradas y entre los puntos suspensivos que imprimen un ritmo elegante, sugerente y atrevido.

A pesar de que Willy tiene amoríos explícitos con algunas actrices de su compañía, es capaz de reprobar el comportamiento de su esposa: «¿Cómo puede gustarte una mujer?. ${ }^{59}$, le reprocha; cree que Colette lo hace solo como una venganza y no por un genuino sentimiento de plenitud hacia otra de su mismo sexo. De esta manera, él rechaza la idea del encuentro sáfico como placentero debido a la deses-

57 Ibidem, p. 64.

58 Ibidem, p. 67.

59 Ibidem, p. 69. 
tabilización que le provoca y la transfiere: «Tu novia te está complicando la creatividad... ${ }^{60}$, le espeta a Colette cuando ella no se siente satisfecha con el ensayo de la escena que acaban de presenciar.

Este ambiente de tiranía doméstica y profesional será motivo para intentar escapar del círculo viciado que la envuelve, le proporciona energía para afanarse en su escritura y finalmente le dará el impulso para ser otra persona, más llena y libre. Ella determina abandonar a su marido. Y como último esfuerzo, Willy intenta disuadirla pero con posturas homofóbicas que poco ayudarán en su objetivo: «Entiende -le dice-: las novias no son sanas... a menos que seas hombre, claro ${ }^{61}$; y más adelante: «... No estabas así antes de que llegara tu novia fea... [...]. Fea y además lesbiana...." ${ }^{62}$.

Como lo mencionan Marina López Martínez y Mercedes Sanz, los personajes concebidos por la escritora Colette «expresan su liberación interna a golpe de palabra, fuente fluida donde anidan deseos y roces ${ }^{63}$. Esas cualidades que se asocian al realismo vital e intenso van a ser referencia para la edificación del plano pausado y fresco de la pieza de Ximena Escalante. Las angustias, miedos, certezas y dudas se reflejan tanto en los propios tratamientos de la escritora Colette acerca de la mujer como en la pieza dramática de mismo nombre y en donde la práctica sáfica es evidente a partir del estado de cosas que convergen alrededor del personaje y que opera a su vez como una estrategia de liberación.

Interesa hacer notar que en este drama, al igual que en la producción literaria de la Colette «real», se plantea una postura no androcéntrica y alejada de los estereotipos o lugares comunes, más enfocada a la exploración y libre elección, que considera la sexualidad diversa de la mujer, la demencia de la opresión patriarcal que va a conducir a sus protagonistas hacia la búsqueda de la auténtica identidad, y finalmente $-\mathrm{y}$ con ello mismo- la liberación pensada en su sentido más amplio.

La auténtica escritora francesa concibió a Claudine como una chica rebelde, colegiala impetuosa, brillante, con una sexualidad abierta que muestra sin inconvenientes sus preferencias, y a Mme. René Néré, quien ha sido «educada tradicionalmente, casada muy joven con un hombre mayor que, lejos de cuidarla y protegerla, la tiene a su lado como una presa, como una más de sus conquistas» ${ }^{64}$ y que posee un mayor ejercicio de autorreflexión para hacer un análisis de sí misma y de la tiranía a que está sometida por el marido. En consecuencia, el personaje Colette de la pieza dramática aquí referida va a estar armado considerando una selectiva reunión de ambas caracterologías, logrando crear de esta manera a una protagonista de alto registro que si bien da muestras de una perversión inducida y de un deterioro físico

${ }^{60}$ Ibidem, p. 72.

${ }^{61}$ Ibidem, p. 79.

${ }^{62}$ Ibidem, p. 88.

${ }^{63}$ M. López Martínez y M. SAnz Gil. «El teatro de Colette o cómo conseguir un buen partido: Gigi». Dossiers Feministes 4: Platós/Platees, núm. 4 (12 de noviembre de 2000). Recuperado de http://www.e-revistes.uji.es/index.php/dossiers/article/view/767/667. Consultado el 11/07/2017.

${ }^{64}$ M.C. García Aguilar. "Gabrielle Colette y la novela feminista». Graffylia (3 de febrero de 2016). http://www.filosofia.buap.mx/Graffylia/1/71.pdf. Consultado el 11/07/2017. 
a merced de la transmisión de la enfermedad venérea, clama por la libertad y la autodeterminación como fines más preciados.

Quiero mencionar final y brevemente el caso de Sabina Berman, quien va a hacer alguna referencia hacia la experiencia sexual entre mujeres, que aparece específicamente en su pieza dramática Testosterona, publicada en 2013, como parte de la bisexualidad que practica el personaje femenino.

Esta obra desarrolla un enfrentamiento verbal y agresivo entre Antonio, el director de una importante compañía periodística quien busca con urgencia su reemplazo ante su inminente retiro, y Miky, la sagaz subdirectora de investigación que ambiciona esa posición que en breve quedará vacante. Sin embargo, la competencia por la plaza, que es el motor mismo de la pieza, va a ser salvaje: «El líder más fuerte ocupará la dirección y el otro recogerá las cosas de su escritorio y tendrá que irse" ${ }^{65}$, le aclara Antonio en entrevista a la aspirante.

La pieza posee manejos muy eficaces del lenguaje y giros insospechados que mantienen la tensión de las escenas, que van a encaminarse en este caso para describir el mundo laboral sexista de nuestro tiempo, el poder y las férreas posiciones machistas y misóginas. El asunto sexual será aquí un tópico constante e intenso: en la brevedad que marca el tiempo de la acción, los dos personajes desenmascaran sus miedos y recelos velados, aventurándose incluso a sostener un encuentro íntimo que permitirá tensar todavía más las situaciones que la obra plantea.

Durante el desvelamiento de intimidades, trampas y secretos, Miky posiciona su práctica como una mujer bisexual que tiene sexo casual los fines de semana, y aclara: «No soy lesbiana. [...]. Además, detesto la palabra lesbiana. Prefiero homosexual. Homo: igual, que no hombre. Sexual: relativo al sexo" ${ }^{66}$. Sin ninguna carga moralizante en la obra, la experiencia lésbica se expresa disfrutable, abierta aunque todavía morbosa para las esferas del poder. Puesto que no es éste el tema de la pieza, la obra planea de manera indirecta colocar las prácticas sexuales entre mujeres dentro de la normalización y apoyar el rompimiento de la mirada hegemónica.

Sabina Berman, dramaturga y periodista declara: «Lo gay me encanta porque significa alegría; me parece fantástico y tiene una larga tradición en el lenguaje» ${ }^{67}$.

\section{CONCLUSIONES}

En este estudio se pudo advertir que desde la década de los años cincuenta del siglo pasado con algunas piezas específicas de José Revueltas y Rosario Castellanos, se da presencia a los temas lésbicos en el teatro de México, aunque mediante fórmulas sutiles, tibias y que no son frontales en su desvelamiento. Esta cualidad se

${ }^{65}$ S. Berman. Testosterona, en El narco negocia con Dios. México: El Milagro/LATR Books/ CONACULTA, 2013, pp.105-187.

${ }_{66}$ Ibidem, p. 124-125.

67 A. Bertrán. Damas y adamados. Conversaciones con protagonistas de la diversidad sexual. México: Ediciones B, 2017. 
atribuye tanto a las fórmulas de exposición imperantes como también al marcado nacionalismo preconizado desde el gobierno de ese país, tan en boga en la temporalidad a que pertenecen las producciones en cuestión.

Por otro lado, a pesar de la carpeta de textos dramáticos cuya anécdota está cimentada en la práctica homoerótica entre varones, no será hasta finales de la centuria cuando el tópico sáfico se extienda de manera pronunciada. Las piezas lésbicas dan cuenta, sobre todo, de lo pecaminoso de la preferencia diversa ante la mirada de la sociedad heteronormativa, y la repetición o imitación de algunas actitudes machistas que imperan en el desarrollo de las situaciones.

Las elecciones sexuales en muchos de los casos, y como se ha revisado, deben guardarse como un secreto, propiciando el desasosiego y la infelicidad de los personajes atraídos por otras mujeres, pues el señalamiento acusador habrá de resultar todavía más elocuente. Sin embargo, en textos más recientes en el tiempo, se advierten exposiciones en las que la vida para las protagonistas se hace más disfrutable; inclusive hay espacio para realizar lecturas hasta sardónicas de la heteronormatividad y el patriarcado, a partir también de la práctica performativa que abandona el formato escénico tradicional y se aventura a hacer intervenciones en la vida cotidiana.

El recorrido de este estudio culmina con el trabajo de las escritoras Elena Guiochíns, Ximena Escalante y Sabina Berman, quienes construyen sus propios espacios expositivos no solo ya como puntales dentro de la dramaturgia mexicana contemporánea sino que, a partir de sus propuestas enunciadas, visibilizan las complejas relaciones sexuales y de convivio entre mujeres. Las tres piezas que cierran el artículo abonan, cada una con su particular impronta, en el campo cada vez más visible de las diversidades sexuales.

Recibido: noviembre de 2018. Aceptado: abril de 2019 


\section{BIBLIOGRAFÍA}

Argüelles, Hugo. El cocodrilo solitario del panteón rococó, en Obras premiadas II, México: UNAM, 1995, pp. 13-106.

Berman, Sabina. Testosterona, en El narco negocia con Dios, México: El Milagro- LATR Books-CONACULTA, 2013, pp. 105-187.

Bertrán, Antonio. Damas y adamados. Conversaciones con protagonistas de la diversidad sexual. México: Ediciones B, 2017.

Castellanos, Rosario. El eterno femenino, en Eduardo Mejía (comp. y notas), Obras II. Poesía, teatro y ensayo, México: Fondo de Cultura Económica, 2014, pp. 363-454.

Castellanos, Rosario. Tablero de damas, en Eduardo Mejía (comp. y notas), Obras II. Poesía, teatro y ensayo, México: Fondo de Cultura Económica, 2014, pp. 279-319.

Escalante, Ximena. Colette, en Encierro, pasión y desesperación, México: El Milagro-UANL-CONACULTA, 2013, pp. 21-99.

Foucault, Michel. Vigilar y castigar. Nacimiento de la prisión. México: Siglo XXI, 2003.

García Aguilar, María del Carmen. "Gabrielle Colette y la novela feminista». Graffylia (3 febrero 2016). http://www.filosofia.buap.mx/Graffylia/1/71.pdf. Consultado el 11/07/2017.

García Barrientos, José-Luis. Cómo se comenta una obra de teatro. México: Secretaría de Cultura DF/Paso de gato, 2012.

Guerrero Guadarrama, Laura. La ironia en la obra temprana de Rosario Castellanos. México: Universidad Iberoamericana/Eón, 2005.

Guerrero Guadarrama, Laura. «La obra oculta de Rosario Castellanos». Revista de Literatura Mexicana Contemporánea, vol. 42, núm. 16 (2009), pp. 7-17.

Guiochíns, Elena. Bellas atroces. México: Anónimo Drama, 2002.

Guiochíns, Elena. Bellas atroces. Tramoya, vol. 120 (2014), pp. 77-108.

LeÑero, Vicente. «Introducción», en La nueva dramaturgia mexicana, México: El Milagro/Consejo Nacional para la Cultura y las Artes, 1996, pp. 9-39.

Liera, Óscar. Los camaleones, en La Piña y la Manzana. Viejos juegos en la dramática, México: Universidad Nacional Autónoma de México, 1982, pp. 37-43.

López Martínez, Marina y Mercedes Sanz Gil. "El teatro de Colette o cómo conseguir un buen partido: Gigi». Dossiers Feministes 4: Platós/Platees, vol. 4 (12 de noviembre de 2000). http:// www.e-revistes.uji.es/index.php/dossiers/article/view/767/667. Consultado el 11/07/2017.

Magaña, Sergio. Los signos del Zodiaco (24 de septiembre de 2002). http://www.dramavirtual. $\mathrm{com} / 2014 / 11 /$ los-signos-del-zodiaco-sergio-magana.html noviembre 28 de 2014 . Consultado el 27/06/2016.

Ocampo, Aurora M. Diccionario de escritores mexicanos, tomo I A-Ch, México: UNAM, 1988.

Quintanilla-Pérez, Selena. Amor prohibido (2 de febrero de 2012). https://www.youtube.com/ watch?v=dvfZ95ueOcQ. Consultado el 30/06/2017.

Ramírez-Cancio, Marlene y Clara. Entrevista a Jesusa Rodríguez y Liliana Felipe. 23 de agosto de 2001. http://hemisphericinstitute.org/hemi/es/hidvl-profiles/item/1598-habito-int-jesusa-lili. Consultado el 28/09/2015. 
Revueltas, José. El cuadrante de la soledad, en Obra reunida IV. El cuadrante de la soledady dos obras de teatro, México: Era/Centro Nacional de las Artes/Gobierno del Estado de Durango, 2014, pp. 393-452.

Rocco, Alessandro. "José Revueltas dramaturgo y guionista: la obra teatral El cuadrante de la sole$d a d$, características cinematográficas y relaciones intertextuales con algunos guiones cinematográficos». Graffylia, vol. 19 (13 mayo 2014). http://cmas.siu.buap.mx/portal_pprd/ work/sites/filosofia/resources/PDFContent/1159/02.pdf. Consultado el 27/06/2017.

RodríGuez, Antoine. «Indecentes y disidentes obras queer de teatro latinoamericano». Tramoya, vol. 120 (2014), pp. 5-12.

SABSAY, Leticia. «IV. Políticas queer, ciudadanías sexuales y decolonización», en Diego Falconí Trávez, Santiago Castellanos y María Amelia Viteri (eds.). Resentir lo queer en América Latina: diálogos desde / con el Sur, Barcelona-Madrid: Egales, 2014, pp. 45-58.

Salcedo, Hugo. Selena, la reina del tex-mex». México: Universidad Autónoma de Nuevo León, 1999.

Salinas, Gilda. Primera mudanza, en Más teatro gay, México: Pax, 2002, pp. 103-124.

Téllez-Pons, Sergio. La sintesis rara de un siglo loco. México: Fondo Editorial Tierra Adentro, 2017.

Ubersfeld, Anne. Semiótica teatral. Madrid: Cátedra/Universidad de Murcia, 1989.

Urtusástegui, Tomás. Inseminación artificial, en VV. AA., Teatro gay, México: Pax, 2002, pp. 79-90.

Urtusástegui, Tomás. «Prólogo. El teatro sale del clóset», en VV. AA., Teatro gay, México: Pax, 2002, pp. v-VII.

VAldÉs Medellín, Gonzalo. «Prólogo. Gabriela Ynclán: En el corazón mismo de nuestras raigambres», en Mujeres de tierra y fuego, México: Ariadna, 2016, pp. 9-14.

Ynclán, Gabriela. Casa de adobe, en Mujeres de tierra y fuego, México: Ariadna, 2016, pp. 75-102. 
